\title{
Interface Formation and Phase Distribution Induced by Co/SiC Solid State Reactions
}

\author{
Chang Sung Lim ${ }^{1}$, Jung Soo $\mathrm{Ha}^{2}$, Jung Ho Ryu ${ }^{3}$, Keun Ho Auh ${ }^{3}$, In-Tae Bae ${ }^{4}$, \\ Manabu Ishimaru ${ }^{5}$ and Yoshihiko Hirotsu ${ }^{5}$ \\ ${ }^{1}$ Institute of Advanced Materials, CPRC, Hanseo University, Seosan 356-820, Korea \\ ${ }^{2}$ Department of Materials Science and Engineering, Andong National University, Andong 760-749, Korea \\ ${ }^{3}$ Department of Ceramic Engineering, CPRC, Hanyang University, Seoul 133-791, Korea \\ ${ }^{4}$ Department of Materials Science and Engineering, Osaka University, Osaka 565-0871, Japan \\ ${ }^{5}$ The Institute of Scientific and Industrial Research, Osaka University, Osaka 567-0047, Japan
}

Interface formation and phase distribution by the solid-state reactions between thin sputtered cobalt films and $\mathrm{SiC}$ were studied at temperatures between 1023 and $1723 \mathrm{~K}$ for various times. The reaction with the formation of silicides and carbon was first observed above $1123 \mathrm{~K}$. At $1323 \mathrm{~K}$, and as the reaction proceeded, the initially formed $\mathrm{Co}_{2} \mathrm{Si}$ layer converted to $\mathrm{CoSi}$. The deposited cobalt thin film reacted completely with $\mathrm{SiC}$ after annealing at $1323 \mathrm{~K}$ for $0.5 \mathrm{~h}$. The thermodynamically stable $\mathrm{CoSi}$ is the only observed silicide in the reaction up to $1723 \mathrm{~K}$. A reaction model and a thermodynamic argument are proposed to interpret the interface formation and phase distribution of this system.

(Received January 7, 2002; Accepted March 26, 2002)

Keywords: silicon carbide, cobalt film, reaction product, interface formation, phase distribution, carbon precipitation, interfacial reaction model, thermodynamic considerations

\section{Introduction}

The study of metal-ceramic interfacial bonding and its reactions is of great interest in materials science because of the technological applications of devices fabricated from both metal and ceramic components. ${ }^{1-4)} \mathrm{SiC}$ is presently considered as a promising semiconductor for high-power electronic devices, owing to its high thermal and chemical stability. For many applications it is important that the fundamentals of phase distribution and interface chemistry by solid state reactions between metals and ceramics are fully understood. Recently, several studies ${ }^{5-7)}$ have been reported to develop some basic understanding on the physical and chemical interactions at the metal-SiC interfaces. Several transition metals have been evaluated as ohmic contacts for $\mathrm{SiC}$. The contact resistivities have been related to the evolution of related phase formation of the silicides in the metal/SiC interface reaction and the behavior of free carbon remaining after the metal/SiC interface reaction. ${ }^{8,9)}$

In the case of the use of metals forming silicides on $\mathrm{SiC}$ substrates at low temperatures, many metals have a strong tendency to interdiffuse through semiconductor-metal interfaces and most metals readily form carbides or silicides. A thorough characterization and understanding of metal-SiC interfaces, in terms of reactivity and thermal stability, is therefore crucial in the design of $\mathrm{SiC}$ devices. Cobalt could be used to make good high-temperature contacts for utilizing the properties of SiC. Making a suitable material for metallization is also of specific interest because of its silicides-forming tendency at low temperatures. A few detailed studies ${ }^{7,9,10)}$ of the interaction of cobalt with $\mathrm{SiC}$ at various temperatures have been reported. However most of the works were phenomenological in nature because of the complex chemistry of interface formations, and the mechanisms proposed by the works were somewhat obscure because of the complicated in- terface reactions. Therefore, more detailed investigations of the interface formation and phase distribution of the $\mathrm{Co} / \mathrm{SiC}$ reactions are required for improved understanding of $\mathrm{Co} / \mathrm{SiC}$ reaction interface.

In this work, we investigated the interface formation and phase distribution of solid state $\mathrm{Co} / \mathrm{SiC}$ reactions using thin cobalt films sputtered on SiC. The surface morphology, reaction products and interface structure are studied in the temperature range between 773 and 1723 K. Furthermore, a thermodynamic argument and a reaction model are proposed to interpret the interface reaction of $\mathrm{Co} / \mathrm{SiC}$ system.

\section{Experimental Details}

The materials used for the experiments were highly dense sintered $\alpha$-SiC from "E1ektroschmelzwerk Kempten", ESK, and thin sputtered cobalt films. The polycrystalline SiC contained 1.5 mass $\%$ total impurities, such as carbon and aluminum. The SiC plates were cut into small pieces with a diameter of $20 \mathrm{~mm}$ and a thickness of $3 \mathrm{~mm}$ and ground with a $\mathrm{BN} / \mathrm{C}$ disk. The ground $\mathrm{SiC}$ samples were then polished using diamond pastes of $30,15,3,1 \mu \mathrm{m}$. Cobalt films were sputterdeposited on to the polished $\mathrm{SiC}$ substrates in a commercial sputter equipment (Leybold, type Z-400). A magnetron-type D.C. sputtering source was used to deposit the coatings. The growth rate of cobalt films was calculated to be $11.7 \mathrm{~nm} / \mathrm{min}$ under the condition used (D.C. potential $400 \mathrm{~V}$, partial pressure of $\operatorname{Ar} 4.0 \times 10^{-2} \mathrm{mPa}$ ). The applied film thickness was fixed at $2.0 \mu \mathrm{m}$ for this study. This thickness allows the penetration of the $\mathrm{Cu} K_{\alpha}$ beam entirely into the reaction zone by $\mathrm{X}$-ray diffraction analysis (XRD). The couples of SiC with thin sputtered cobalt films were annealed at temperatures between 1023 and $1723 \mathrm{~K}$ for $0.5-2 \mathrm{~h}$, in a high temperature vacuum furnace. The heating rate was set between 20 and $30 \mathrm{Kmin}^{-1}$ and the cooling rate between 5 and $10 \mathrm{Kmin}^{-1}$. 


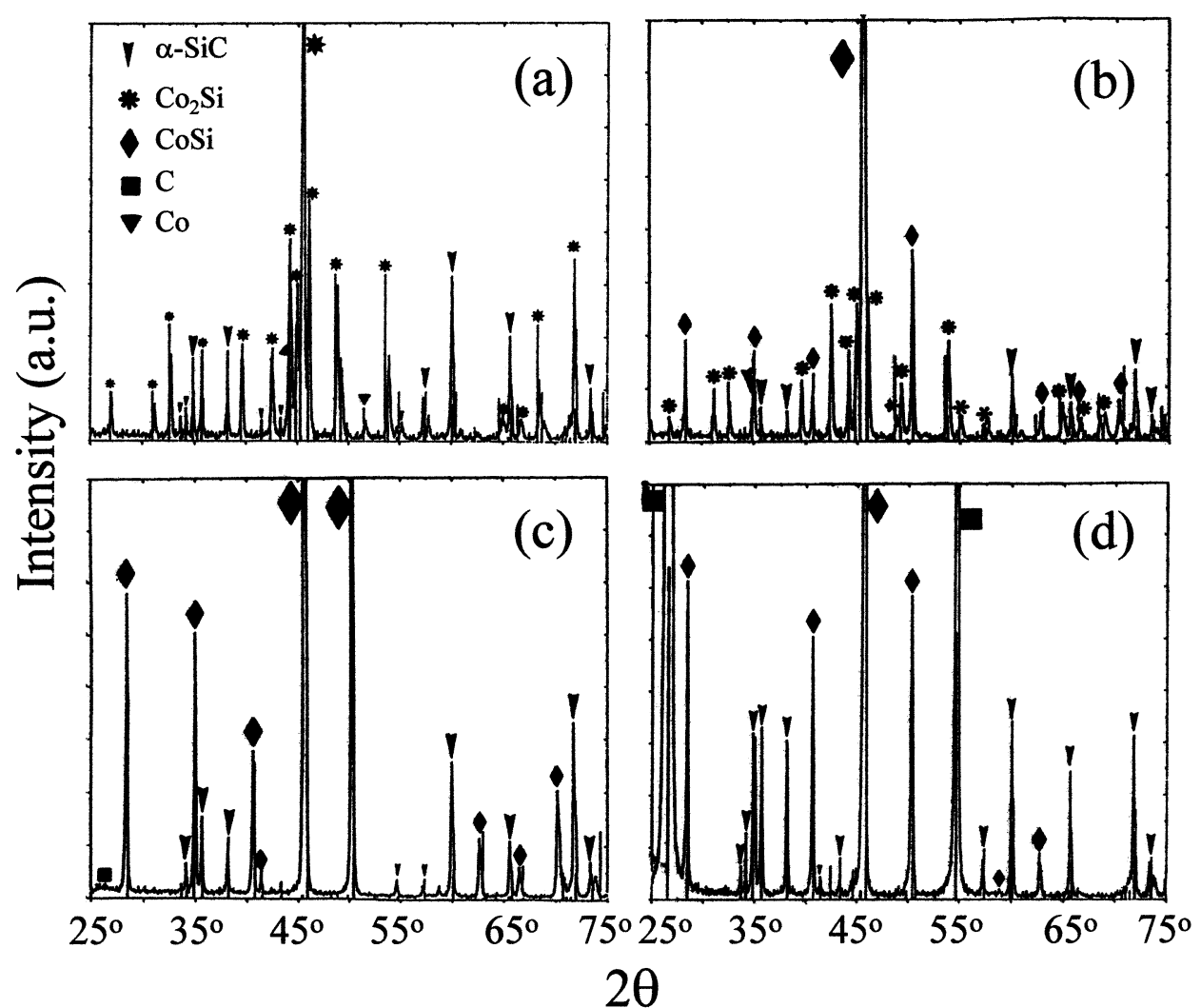

Fig. 1 XRD patterns of the $\mathrm{Co} / \mathrm{SiC}$ reaction couples after annealing at (a) $1123 \mathrm{~K}$ for $4 \mathrm{~h}$, (b) $1323 \mathrm{~K}$ for $0.5 \mathrm{~h}$, (c) $1323 \mathrm{~K}$ for $2 \mathrm{~h}$ and (d) $1723 \mathrm{~K}$ for $0.5 \mathrm{~h}$.

For the prediction of all reaction products, the qualitative process of the reaction in $\mathrm{SiC}$ with thin sputtered cobalt films was estimated by determining phase fractions from relative XRD peak intensities of at least three coincidence-free reflections. The polished cross-sections were investigated using scanning electron microscopy (SEM). Quantitative atomic concentration profiles of silicon, carbon and cobalt were measured using electron probe microanalysis (EPMA). Microstructures of the thermal annealed specimens were also examined using a JEOL JEM-3000F transmission electron microscope (TEM) operating at $300 \mathrm{kV}$. Cross-sectional TEM samples were prepared by gluing an annealed $\mathrm{Co} / \mathrm{SiC}$ to the surface of another one, cutting cross-sections of the sample (perpendicular to the film surface), and using a tripod polishing technique to thin the specimens prior to ion milling with $4 \mathrm{keV} \mathrm{Ar}^{+}$ions.

\section{Experimental Results}

Annealing experiments were performed at temperatures ranging from 1023 to $1723 \mathrm{~K}$. In most cases, thin cobalt films were well coupled with $\mathrm{SiC}$ after annealing above $1123 \mathrm{~K}$. Figure 1 shows XRD patterns of the $\mathrm{Co} / \mathrm{SiC}$ reaction couples after annealing at (a) $1123 \mathrm{~K}$ for $4 \mathrm{~h}$, (b) $1323 \mathrm{~K}$ for $0.5 \mathrm{~h}$, (c) $1323 \mathrm{~K}$ for $2 \mathrm{~h}$ and (d) $1723 \mathrm{~K}$ for $0.5 \mathrm{~h}$. The identification of reaction products was confirmed by determining the relative XRD peak intensities. Below $1123 \mathrm{~K}$, no reaction was observed. At $1123 \mathrm{~K}$, most of the cobalt-layer reacted and formed the silicide $\mathrm{Co}_{2} \mathrm{Si}$ (Fig. 1(a)). No carbide formation, neither $\mathrm{Co}_{2} \mathrm{C}$ nor $\mathrm{Co}_{3} \mathrm{C}$ was detected by XRD. At $1323 \mathrm{~K}$ the entire cobalt film was consumed after $0.5 \mathrm{~h}$ (Fig. 1(b)). At this temperature, the amount of CoSi phase increased with annealing time by decreasing the fraction of $\mathrm{Co}_{2} \mathrm{Si}$ phase. $\mathrm{Co}_{2} \mathrm{Si}$ was fully consumed after $2 \mathrm{~h}$ ( $c f$., Figs. 1(b) and (c)). The same reaction stage was reached at $1523 \mathrm{~K}$ after $0.5 \mathrm{~h}$. After $2 \mathrm{~h}$ at $1523 \mathrm{~K}$ small quantities of graphite could be detected, presumably developing by the graphitization of carbon formed through the reaction $\mathrm{Co}+\mathrm{SiC}=\mathrm{CoSi}+\mathrm{C}$. The quantity of formed graphite increased with the annealing temperature and time above $1523 \mathrm{~K}$. At $1723 \mathrm{~K}$, graphite was detected by $\mathrm{XRD}$ as the predominant reaction product and had a (001) preferred orientation with respect to the surface of substrate (Fig. 1(d)).

Figure 2 shows the surface morphology of the reaction couple of $\mathrm{Co} / \mathrm{SiC}$ after annealing at (a) $1323 \mathrm{~K}, 2 \mathrm{~h}$ and (b) $1723 \mathrm{~K}, 0.5 \mathrm{~h}$. The thickness of the cobalt film on the SiC substrate was fixed at $2 \mu \mathrm{m}$. At $1323 \mathrm{~K}$ for $2 \mathrm{~h}$, the surface morphology showed shadow contrasts with pores and cracks (Fig. 2(a)). At $1723 \mathrm{~K}$ for $0.5 \mathrm{~h}$, severe reactions were observed among the randomly distributed precipitates on the surface (Fig. 2(b)). On this sample, graphite formation was identified by XRD analysis in Fig. 1(d). Therefore, at this temperature of $1723 \mathrm{~K}$ graphites were predominantly precipitated out of the surface of CoSi.

Figure 3 shows the EPMA line scan for cobalt, carbon and silicon over the cross-sectional $\mathrm{Co} / \mathrm{SiC}$ reaction zone after annealing at $1123 \mathrm{~K}, 4 \mathrm{~h}$, showing the distinguishable boundary between $\mathrm{Co}$ and $\mathrm{Co}_{2} \mathrm{Si}+\mathrm{C}$ regions. The corresponding phase distribution is also noted on this diagram. On the surface, a $\mathrm{Co}$ region was identified. In the areas adjacent to the $\mathrm{SiC}$ interface, a mixture of $\mathrm{Co}_{2} \mathrm{Si}$ with carbon was formed. The phase distribution of the reaction zone at $1123 \mathrm{~K}, 4 \mathrm{~h}$ can be 


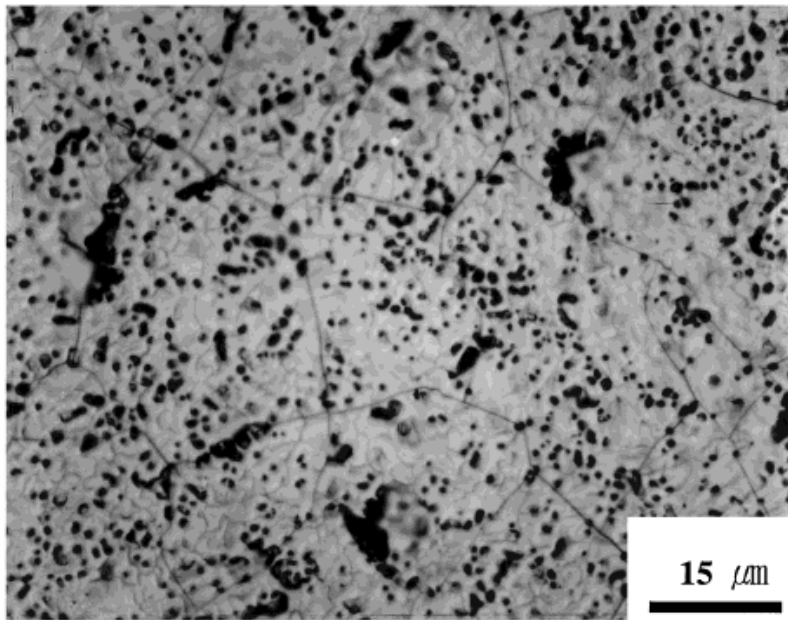

(a)

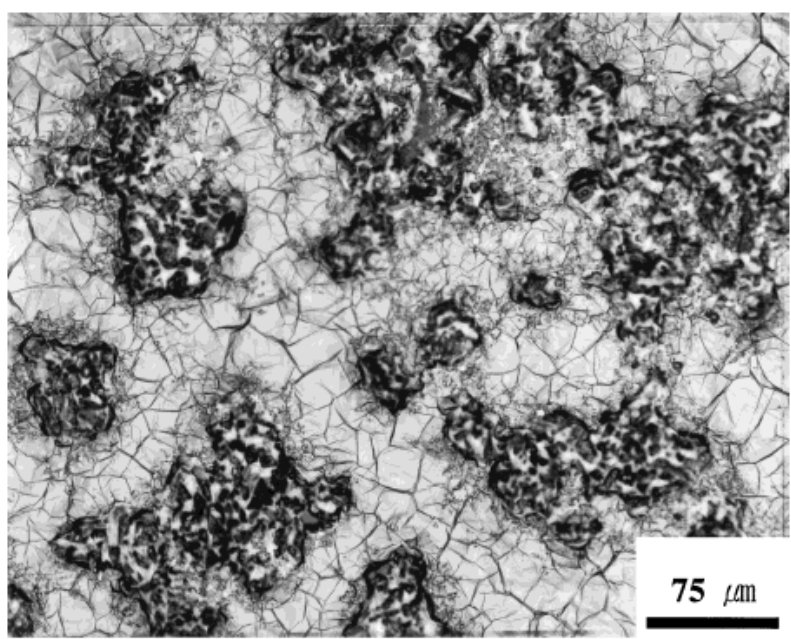

(b)

Fig. 2 Surface morphology of the reaction couples of $\mathrm{Co} / \mathrm{SiC}$ after annealing at (a) $1323 \mathrm{~K}, 2 \mathrm{~h}$ and (b) $1723 \mathrm{~K}, 0.5 \mathrm{~h}$. The thickness of the cobalt film on the $\mathrm{SiC}$ substrate was fixed at $2 \mu \mathrm{m}$.

expressed by the structure: $\mathrm{Co} / \mathrm{Co}_{2} \mathrm{Si}+\mathrm{C} / \mathrm{SiC}$. This phase distribution will be confirmed later as shown in Fig. 4.

Figure 4 shows cross-sectional scanning electron micrographs of the $\mathrm{Co} / \mathrm{SiC}$ reaction zone after annealing at (a) $1323 \mathrm{~K}, 0.5 \mathrm{~h}$ and (b) $1323 \mathrm{~K}, 2 \mathrm{~h}$. At this annealing temperature cobalt-silicide layers extend to $5 \mu \mathrm{m}$ below the surface, and deposited Co thin film is completely exhausted as described above. In Fig. 4(a) a wide layer of $\mathrm{CoSi}+\mathrm{C}$ was observed with the carbon precipitates in the lower region neighboring the $\mathrm{SiC}$, while a relatively thin layer of $\mathrm{Co}_{2} \mathrm{Si}$ was observed without carbon in the upper region. The phase distribution of the reaction zone at $1323 \mathrm{~K}, 0.5 \mathrm{~h}$ can be described by the structure: $\mathrm{Co}_{2} \mathrm{Si} / \mathrm{CoSi}+\mathrm{C} / \mathrm{SiC}$, which was identified by EPMA. In Fig. 4(b) a wide layer of $\mathrm{CoSi}+\mathrm{C}$ was observed with the precipitations of carbon in the lower region neighboring the $\mathrm{SiC}$, while a relatively thin layer of $\mathrm{CoSi}$ was observed without carbon in the upper region. The phase distribution of the reaction zone at $1323 \mathrm{~K}, 2 \mathrm{~h}$ can be described by the structure: $\mathrm{CoSi} / \mathrm{CoSi}+\mathrm{C} / \mathrm{SiC}$. Depending on the annealing time at this temperature, the relative quantities of $\mathrm{CoSi}$ increased simultaneously, while $\mathrm{Co}_{2} \mathrm{Si}$ decreased. It seems that $\mathrm{Co}_{2} \mathrm{Si}$ is

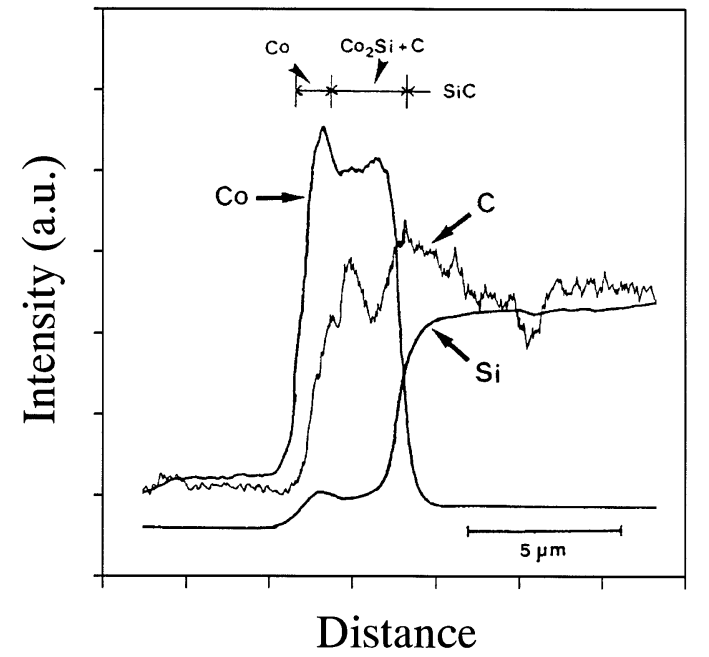

Fig. 3 EPMA line scan for cobalt, carbon and silicon over the cross-sectional $\mathrm{Co} / \mathrm{SiC}$ reaction zone after annealing at (a) $1123 \mathrm{~K}, 4 \mathrm{~h}$ showing the distinguishable boundary between $\mathrm{Co}$ and $\mathrm{Co}_{2} \mathrm{Si}+\mathrm{C}$ regions.
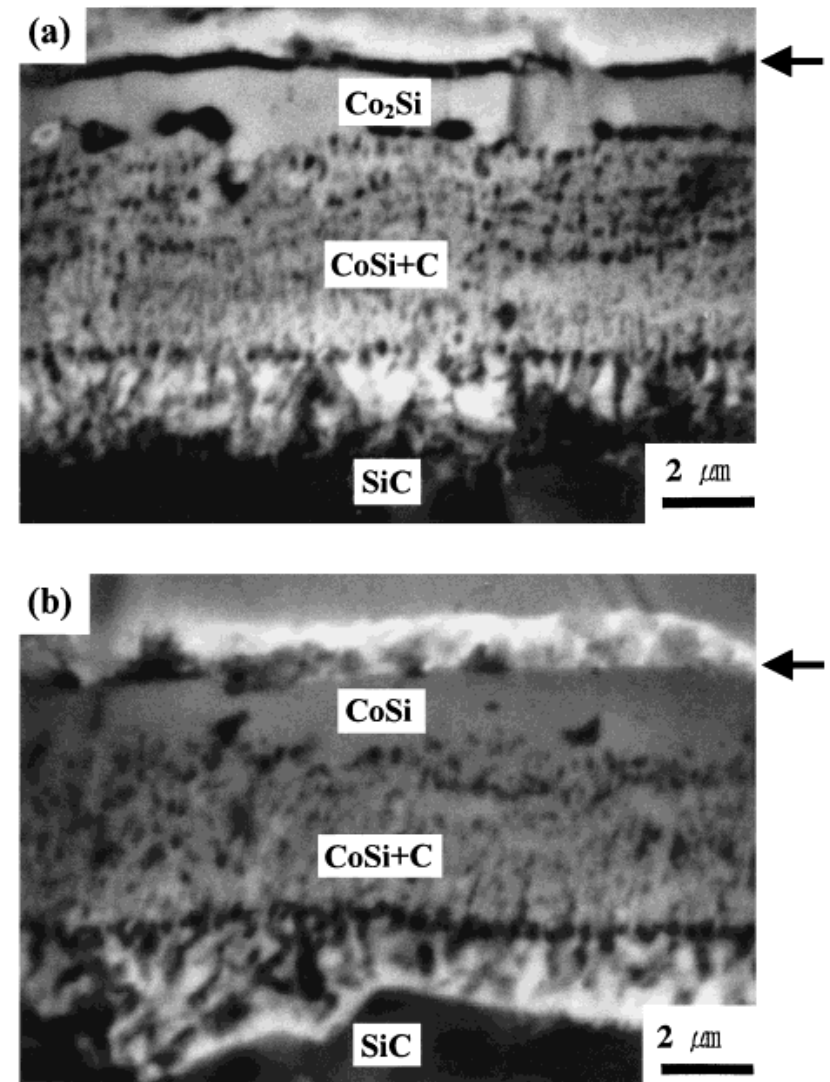

Fig. 4 Scanning electron micrograph showing the cross-sectional views of the $\mathrm{Co} / \mathrm{SiC}$ reaction zone after annealing at (a) $1323 \mathrm{~K}, 0.5 \mathrm{~h}$ and (b) $1323 \mathrm{~K}, 2 \mathrm{~h}$. The arrows indicate the top of the reaction layers.

the first reaction product between cobalt and $\mathrm{SiC}$ under these conditions. The migration rate of silicon in this phase is assumed to be much higher than that of carbon, indicating the progress of the reaction up to the full consumption of metallic cobalt. The carbon remains along the $\mathrm{Co}_{2} \mathrm{Si} / \mathrm{SiC}$ interface. On increasing the amount of silicon $\mathrm{Co}_{2} \mathrm{Si}$ forms $\mathrm{CoSi}$, which probably dissolves carbon which is deposited randomly in this phase region during the cooling process.

To obtain more information on microstructures, the specimens were examined by TEM. Figure 5 shows selected-area 

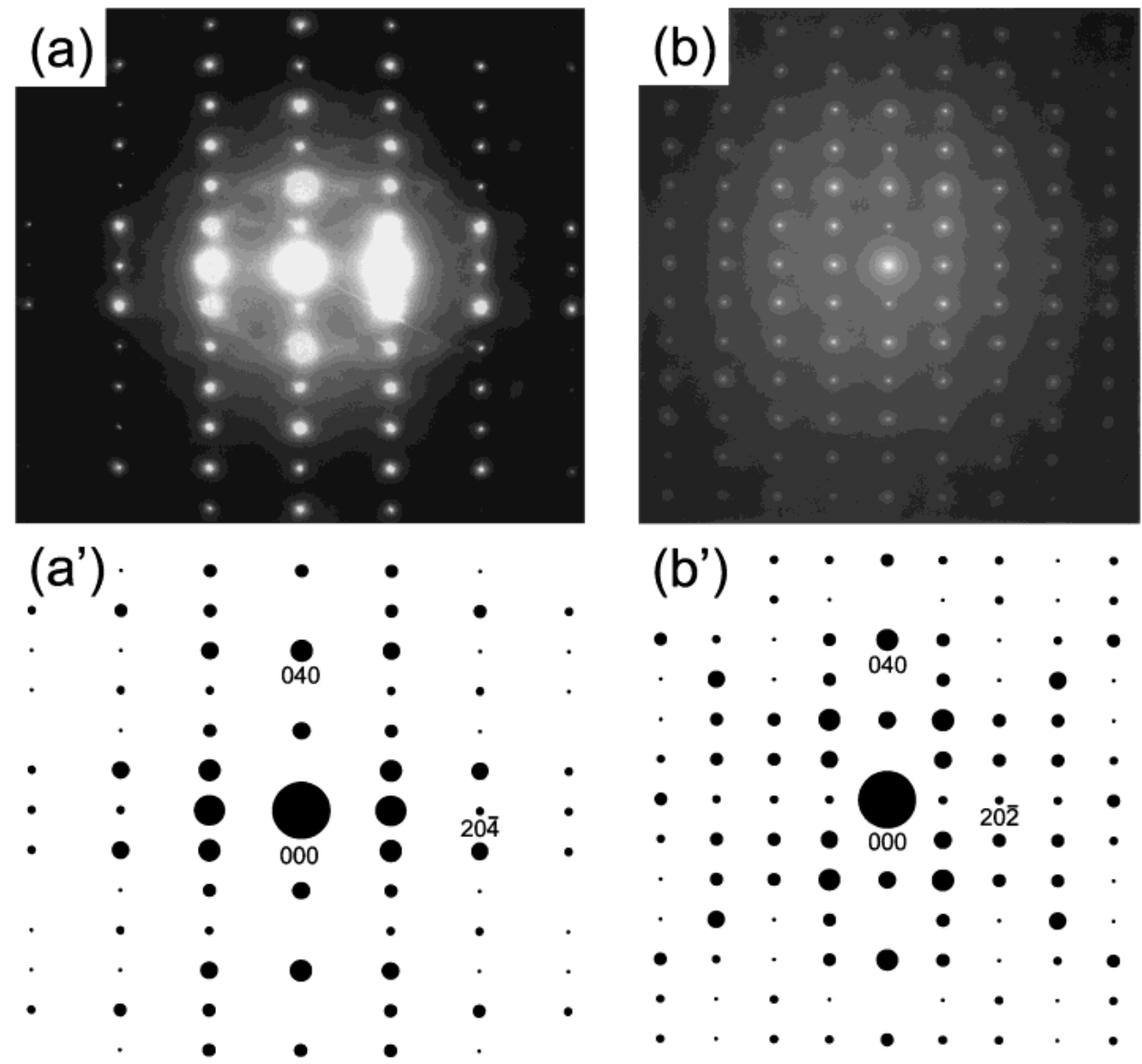

Fig. 5 (a), (b) SAED patterns and $\left(a^{\prime}\right),\left(b^{\prime}\right)$ simulated electron diffraction patterns corresponding to (a), (b).

electron diffraction (SAED) patterns of $\mathrm{Co} / \mathrm{SiC}$ sample annealed at $1323 \mathrm{~K}$ for $2 \mathrm{~h}$. SAED patterns obtained from the reacted layer are displayed in Figs. 5(a) and (b). These patterns were obtained from the different positions of the topmost layer. To identify the crystalline phase of the topmost layer, the structure factor, $F_{h k l}$, where $h k l$ represents a specific Bragg reflection, was calculated for several cobalt-silicides such as $\mathrm{CoSi}\left(\mathrm{P} 2{ }_{1} 3: a=0.4446 \mathrm{~nm}\right), \mathrm{Co}_{2} \mathrm{Si}(\mathrm{Pnma}: a=$ $0.4918 \mathrm{~nm}, b=0.3738 \mathrm{~nm}, c=0.7109 \mathrm{~nm})$, and $\mathrm{CoSi}_{2}$ (Fm $\overline{3} \mathrm{~m}: a=0.5365 \mathrm{~nm}$ ). Based on the calculations of $F_{h k l}$, we have found that the SAED patterns in Figs. 5(a) and (b) are consistent with the (201) and (101) reciprocal lattice planes of CoSi, respectively [Figs. $5\left(\mathrm{a}^{\prime}\right)$ and $\left(\mathrm{b}^{\prime}\right)$ ]. That is, the topmost layer consists of CoSi. The results of electron diffraction experiments are consistent with those of X-ray diffraction experiments [Fig. 1(c)]. The mottled layer, as indicated by $\mathrm{CoSi}+\mathrm{C}$ in Fig. 4(b), is also $\mathrm{CoSi}$, but energy-dispersive $\mathrm{X}$-ray spectroscopy measurements indicated that carbon-rich precipitates (black regions in the mottled layer) are formed in this layer. These results are in agreement with those obtained by EPMA.

\section{Discussion}

The reaction between cobalt thin film and $\mathrm{SiC}$ leads to the formation of cobalt silicides accompanied by carbon precipitates. It is worthwhile discussing the interface formation, phase distribution and thermodynamic stability in the reac-
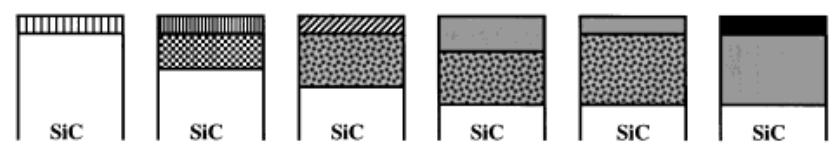

Room

temperature

$1123 \mathrm{~K} 4 \mathrm{~h}$

$23 \mathrm{~K} 0.5 \mathrm{~h}-1323 \mathrm{~K} 2 \mathrm{~h}$

$1523 \mathrm{~K} 2 \mathrm{~h} \quad 1723 \mathrm{~K} 0.5 \mathrm{~h}$
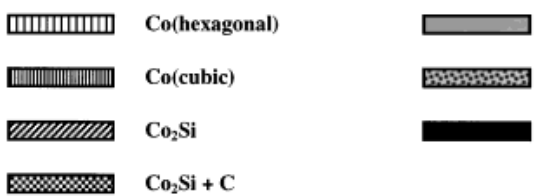

$\operatorname{CoSi}$

$\mathrm{CoSi}+\mathrm{C}$

$\mathrm{C}_{\mathrm{G}}($ Graphite)

Fig. 6 Reaction model of the $\mathrm{Co} / \mathrm{SiC}$ interface formation and phase distribution.

tion zone. A reaction model of the $\mathrm{Co} / \mathrm{SiC}$ interface formation and phase distribution is proposed in Fig. 6. At $1123 \mathrm{~K}$, most of the cobalt-layer reacted and initially formed the silicide $\mathrm{Co}_{2} \mathrm{Si}$. The interfacial sequence for the phase distribution at this temperature can be described by the structure: $\mathrm{Co} / \mathrm{Co}_{2} \mathrm{Si}+\mathrm{C} / \mathrm{SiC}$. Unreacted cobalt was crystallized as a cubic modification, which identified near $52^{\circ}$ in $2 \theta$ by XRD in Fig. 1(a) after heat treatment above $1123 \mathrm{~K}$. Fujimura and Tanaka $^{10)}$ also examined the formation process of cobalt silicide during annealing using in situ X-ray diffraction, and reported the hexagonal Co transforms into the cubic Co. The 
Table 1 Gibb's free energy of possible reactions for $\mathrm{Co} / \mathrm{SiC}$ system at $1323 \mathrm{~K}$.

\begin{tabular}{lc}
\hline Possible reaction & Gibb's free energy $(\mathrm{kJ} / \mathrm{mol})$ \\
\hline $\mathrm{Co}+1 / 2 \mathrm{SiC}=1 / 2 \mathrm{Co}_{2} \mathrm{C}+1 / 2 \mathrm{Si}$ & 27.5 \\
$1 / 2 \mathrm{Co}+\mathrm{SiC}=1 / 2 \mathrm{CoSi}_{2}+\mathrm{C}$ & 2.4 \\
$\mathrm{Co}+\mathrm{SiC}=\mathrm{CoSi}+\mathrm{C}$ & -37.4 \\
$2 \mathrm{Co}+\mathrm{SiC}=\mathrm{Co}_{2} \mathrm{Si}+\mathrm{C}$ & -67.0 \\
$1 / 2 \mathrm{Co}+\mathrm{Si}=1 / 2 \mathrm{CoSi}_{2}$ & -46.9 \\
$\mathrm{Co}+\mathrm{Si}=\mathrm{CoSi}_{20} \mathrm{Si}=\mathrm{Co}_{2} \mathrm{Si}$ & -86.7 \\
$2 \mathrm{Co}$ & -99.6 \\
\hline
\end{tabular}

deposited cobalt thin film reacted completely with $\mathrm{SiC}$ after annealing at $1323 \mathrm{~K}$ for $0.5 \mathrm{~h}$. At $1323 \mathrm{~K}$, as the reaction proceeded, the initially formed $\mathrm{Co}_{2} \mathrm{Si}$ layer converted to $\mathrm{CoSi}$. The interfacial sequence for the phase distribution at $1323 \mathrm{~K}, 0.5 \mathrm{~h}$ can be described by the structure: $\mathrm{Co}_{2} \mathrm{Si} / \mathrm{CoSi}+$ $\mathrm{C} / \mathrm{SiC}$. Above $1323 \mathrm{~K}, 2 \mathrm{~h}$ the thermodynamically stable CoSi is the only observed silicide in the reaction up to $1723 \mathrm{~K}$. The interfacial sequence for the phase distribution between $1323 \mathrm{~K}, 2 \mathrm{~h}$ and $1523 \mathrm{~K}, 2 \mathrm{~h}$ can be described by the structure: $\mathrm{CoSi} / \mathrm{CoSi}+\mathrm{C} / \mathrm{SiC}$. Above $1723 \mathrm{~K}$ graphite were predominantly precipitated out of the surface of $\mathrm{CoSi}$ with the following sequence: $\mathrm{C}_{\mathrm{G}} / \mathrm{CoSi} / \mathrm{SiC}$. Fujimura and Tanaka ${ }^{10)}$ suggested a model of $\mathrm{Co} / \mathrm{SiC}$ interface reaction under experimental conditions between 921 and $1573 \mathrm{~K}$. They described that the reaction sequence at high temperatures were $\mathrm{Co} / \mathrm{Co}_{2} \mathrm{Si}+$ $\mathrm{C} / \mathrm{SiC}, \mathrm{Co} / \mathrm{Co}_{2} \mathrm{Si}+\mathrm{CoSi}+\mathrm{C} / \mathrm{SiC}, \mathrm{Co} / \mathrm{CoSi}+\mathrm{C} / \mathrm{SiC}$ and $\mathrm{CoSi}+\mathrm{C} / \mathrm{SiC}$. However, in this work, after consuming the cobalt-layer the reaction layer sequences were suggested by the structure: $\mathrm{Co}_{2} \mathrm{Si} / \mathrm{CoSi}+\mathrm{C} / \mathrm{SiC}, \mathrm{CoSi} / \mathrm{CoSi}+\mathrm{C} / \mathrm{SiC}$ and $\mathrm{C}_{\mathrm{G}} / \mathrm{CoSi} / \mathrm{SiC}$.

Considering the Gibb's free energy, $\Delta G$, for various reactions, the reaction products between cobalt and $\mathrm{SiC}$ could be correlated within this system. Table 1 shows Gibb's free energy of the possible reactions for $\mathrm{Co} / \mathrm{SiC}$ system at $1323 \mathrm{~K}$. The result predicts which phases are stable at the thermodynamic equilibrium. At temperatures of $1323 \mathrm{~K}$, cobalt is known to react with silicon to form various silicides $\mathrm{CoSi}$, $\mathrm{Co}_{2} \mathrm{Si}$ and $\mathrm{CoSi}_{2}$, because the $\Delta G$ values for the formation of these compounds are highly negative. Less negative values are calculated for the corresponding reaction with $\mathrm{SiC}$, i.e.

$$
\mathrm{Co}+\mathrm{SiC}=\mathrm{CoSi}+\mathrm{C} \quad \Delta G=-37.4 \mathrm{~kJ} / \mathrm{mol}
$$

and

$$
\mathrm{Co}+1 / 2 \mathrm{SiC}=1 / 2 \mathrm{Co}_{2} \mathrm{Si}+1 / 2 \mathrm{C} \quad \Delta G=-33.5 \mathrm{~kJ} / \mathrm{mol}
$$

because of the energy needed for $\mathrm{SiC}$ decomposition. The formation of $\mathrm{CoSi}_{2}$ and $\mathrm{Co}_{2} \mathrm{C}$ by the reaction between $\mathrm{SiC}$ and $\mathrm{Co}$ is not thermodynamically possible at this temperature, because of the positive $\Delta G$ value of 2.4 and $27.5 \mathrm{~kJ} / \mathrm{mol}$, respectively. Therefore, the solid state reaction between cobalt and $\mathrm{SiC}$ could be generally described as the formation of $\mathrm{CoSi}+\mathrm{C}$ and $\mathrm{Co}_{2} \mathrm{Si}+\mathrm{C}$, which results in the decomposition of $\mathrm{SiC}$ and the precipitation of carbon. According to the present experimental results, cobalt reacts with $\mathrm{SiC}$ and forms various silicides at the $\mathrm{SiC}$ interface. At $1323 \mathrm{~K}$ the $\mathrm{Co}_{2} \mathrm{Si}$ layer converted to $\mathrm{CoSi}$ and additional carbon precipitates were formed within the CoSi zone. The reason why the $\mathrm{Co}_{2} \mathrm{Si}$ layer con- verted to CoSi is attributed to the availability of more cobalt atoms, as compared to silicon atoms, in the reaction zone because of a faster consumption rate of cobalt. According to reported diffusion data, ${ }^{11-14)}$ cobalt is the dominant diffuser in the $\mathrm{Co}_{2} \mathrm{Si}$ phase. It also diffuses through $\mathrm{Co}_{2} \mathrm{Si}$ and $\mathrm{CoSi}$, and arrives the $\mathrm{SiC}$ interface to react with $\mathrm{SiC}$. After the metallic cobalt layer is completely consumed, cobalt migration takes place from the $\mathrm{Co}_{2} \mathrm{Si}$, resulting in the growth of the CoSi layer. It is possible that CoSi grows at the $\mathrm{Co}_{2} \mathrm{Si} / \mathrm{CoSi}$ and $\mathrm{CoSi} / \mathrm{SiC}$ interfaces, resulting in the growth of $\mathrm{CoSi}$ with heating time and increasing temperature. At $1323 \mathrm{~K}$ for $0.5 \mathrm{~h}$ only carbon precipitation was observed in the CoSi phase, because $\Delta G$ of $\operatorname{CoSi}(-37.4 \mathrm{~kJ} / \mathrm{mol})$ is lower than that of the $\mathrm{Co}_{2} \mathrm{Si}$ phase $(-33.5 \mathrm{~kJ} / \mathrm{mol})$ and could provide the thermodynamic driving force for carbon precipitation.

\section{Summary}

Interface formation and phase distribution of solid state $\mathrm{Co} / \mathrm{SiC}$ reactions using thin cobalt films sputtered on $\mathrm{SiC}$ were investigated at temperatures between 1023 and $1723 \mathrm{~K}$. At $1123 \mathrm{~K}$, most of the cobalt-layer reacted and initially formed $\mathrm{Co}_{2} \mathrm{Si}$. The interfacial sequence for the phase distribution at this temperature was described by the structure of $\mathrm{Co} / \mathrm{Co}_{2} \mathrm{Si}+\mathrm{C} / \mathrm{SiC}$. The deposited cobalt thin film reacted completely with $\mathrm{SiC}$ after annealing at $1323 \mathrm{~K}$ for $0.5 \mathrm{~h}$. At $1323 \mathrm{~K}$, as the reaction proceeded, the initially formed $\mathrm{Co}_{2} \mathrm{Si}$ layer converted to $\mathrm{CoSi}$. The interfacial sequence for the phase distribution at $1323 \mathrm{~K}, 0.5 \mathrm{~h}$ was described by the structure of $\mathrm{Co}_{2} \mathrm{Si} / \mathrm{CoSi}+\mathrm{C} / \mathrm{SiC}$. Above $1323 \mathrm{~K}$ for $2 \mathrm{~h}$, the thermodynamically stable $\mathrm{CoSi}$ is the only observed silicide in the reaction up to $1723 \mathrm{~K}$. The interfacial sequence for the phase distribution between $1323 \mathrm{~K}, 2 \mathrm{~h}$ and $1523 \mathrm{~K}, 2 \mathrm{~h}$ was described by the structure: $\mathrm{CoSi} / \mathrm{CoSi}+\mathrm{C} / \mathrm{SiC}$. Above $1723 \mathrm{~K}$ graphite were predominantly precipitated out of the surface of CoSi with the sequence of $\mathrm{C}_{\mathrm{G}} / \mathrm{CoSi} / \mathrm{SiC}$. The interfacial reaction model of this system has been proposed and discussed in terms of the thermodynamic argument.

\section{REFERENCES}

1) A. Nishimoto, M. Ando, M. Takahashi, M. Aritoshi and K. Ikeuchi: Mater. Trans., JIM 40 (1999) 953-956.

2) T. Ishikawa, M. E. Brito, Y. Inoue, Y. Hirotsu and A. Miyamoto: ISIJ Int. 30 (1990) 1071-1077.

3) M. E. Brito, H. Yokoyama, Y. Hirotsu and Y. Mutoh: ISIJ Int. 29 (1989) 253-258.

4) M. E. Brito, H. Yokoyama, Y. Hirotsu and Y. Mutoh: MRS Int'l. Mtg. on Adv. Mats. 8 (1989) 23-28.

5) T. C. Chou, A. Joshi and J. Wadsworth: J. Mater. Res. 6 (1991) 796-809.

6) W. F. J. Slijkerman, J. Fisher, J. F. van der Veen, I. Ohdomari, S. Yoshida and S. Misawa: J. Appl. Phys. 66 (1989) 666-673.

7) S. W. Park, Y. I. Kim, J. S. Kwak and H. K. Baik: J. Electro. Mat. 26 (1997) 172-177.

8) C. S. Lim, H. Nickel, A. Naoumidis and Gyarmati: J. Mater. Sci. 32 (1997) 6567-6572.

9) C. S. Lim, H. Nickel, A. Naoumidis and Gyarmati: J. Mater. Sci. 31 (1996) 4241-4247.

10) T. Fujimura and S. I. Tanaka: J. Mater. Sci. 34 (1999) 5743-5747.

11) S. S. Lau and J. W. Mayer: J. Appl. Phys. 49 (1978) 4005-4010.

12) G. J. Van Gurp, W. F. Van der Weg and D. Sigurd: J. Appl. Phys. 49 (1978) 4011-4020.

13) F. M. D'Heurle and C. S. Petersson: Thin Solid Films 128 (1985) 283-297.

14) A. P. Bitha and R. Pretorius: Thin Solid Films 93 (1982) 127-133. 
